\title{
La fábula medieval como espacio para la reflexión moral: La torre vigía de Ana María Matute
}

\author{
The Medieval Fable as a Space for Moral Reflection: \\ La torre vigía by Ana María Matute
}

\author{
Magda Potok \\ Uniwersytet im. Adama Mickiewicza w Poznaniu \\ mpotok@amu.edu.pl
}

\begin{abstract}
The first part of the so-called medieval trilogy by Ana María Matute, The Watchtower (1971), approaches the mythical world of the Middle Ages with a manifestly modern sensibility, preoccupied by lack of communication, isolation, violence and the conflictive nature of human relations. The use of inherent properties distinguishing the medieval culture (castles, warriors, weapons, etc.) allows, on the one hand, to accentuate the brutality of the world and, on the other hand, to reach an unreal dimension through the pre-rational imagination (witches, spells, animals in bestiaries, etc.), generating the universal meaning of the story. Focusing the narrative on a teenage character, the writer delves into one of the essential themes of her creation: the discovery of ferocity in human relations. Thus, in this Bildungsroman inscribed in the aesthetics of medievalizing fantasy (with Gothic elements that intensify the terrifying experience), moral problems are discussed, with a special attention to the consequences of affective deficiencies, violence, war, etc.
\end{abstract}

Keywords: Ana María Matute, medievalizing fantasy, Bildungsroman, La torre vigía

En su primer asomo novelístico a la estética de lo irreal, La torre vigía (1971), Ana María Matute aborda una vez más los temas recurrentes de su obra: la conflictividad de las relaciones humanas, marcadas por el rencor y el odio, el desamparo y la soledad del niño, la lucha eterna entre el bien y el mal. La recreación del mundo caballeresco de una Edad Media mítica le sirve para remarcar la violencia, concebida en este entorno como un modo de vida natural. Para ser guerrero uno debe olvi- 
darse de valores altisonantes como el honor y el sacrificio, y aprender a luchar ferozmente por su propio bienestar, sin considerar el daño ocasionado. Cargada de preocupación moral, esta sorprendente fantasía medieval señala las consecuencias de una vida basada en la violencia. Los elementos fantásticos, que alejan la fábula de sus raíces históricas, potencian el carácter universal del texto a modo de parábola, aunque ello no obliga a una interpretación unívoca.

Matute es una de las escritoras más destacadas del siglo XX. Miembro de la Real Academia de la Lengua (1996), fue galardonada con numerosos premios literarios, aunque para el más prestigioso de ellos, el premio Cervantes, tuviera que esperar hasta el año 2010. ${ }^{1}$ A pesar de los vínculos generacionales y temáticos con la narrativa neorrealista de los años 50 y 60, la crítica ha tenido problemas para encuadrar su obra en una corriente o escuela de la época, ya que visiblemente (y declarativamente) Matute no se inscribía en ninguna de ellas. La escritora pertenece a la generación "del medio siglo", cuyos autores, en su gran mayoría, representan la miseria de la posguerra española bajo una estética objetivista y testimonial. Si bien la hegemonía realista en la literatura de la época es cierta, estudios recientes (Roas \& Casas, 2008; Roas, 2017) hacen hincapié en la existencia simultánea e ininterrumpida de formas literarias no miméticas. En los años 40 y 50, según apuntan Casas, Roas y Gregori (2017, pp. 61-67), el cultivo de lo fantástico debe considerarse marginal. No obstante, en algunos autores, incluida Matute, la narración se aleja del objetivismo para ingresar en el ámbito de lo maravilloso o lo alegórico (Casas, Roas \& Gregori, 2017, pp. 61-67). Con respecto a la creación de Matute o la novela de Rafael Sánchez Ferlosio Industrias y andanzas de Alfanhuí (1951), David Roas y Ana Casas (2008) puntualizan que la combinación de fantasía y realidad en estos autores no genera un efecto fantástico, transgresor, sino que deriva hacia el puro ámbito de lo imaginativo (p. 28).

Desde sus comienzos, marcados por la publicación de novelas realistas -Los Abel (1948), Los hijos muertos (1958) y La primera memoria (1959), entre otras- la narrativa de Matute destacó por un tono personal, poético y subjetivo. Santos Sanz Villanueva llega a afirmar que la adhesión de la narradora a la tendencia realista de posguerra supuso una concesión a las circunstancias colectivas. Según el crítico, la anormalidad $^{2}$ de las letras durante el franquismo le impidió volcarse en los procedimientos fantaseadores que le eran connaturales y, solo a finales del franquismo, pudo dedicarse con libertad a la escritura que le gustaba (Sanz Villanueva, 2010, p. 236). Lo cierto es que Matute ha creado un mundo narrativo propio, con un estilo

\footnotetext{
${ }^{1}$ Matute recibió el premio Cervantes a los ochenta y cinco años de edad. Cabe destacar que fue la tercera mujer en ganarlo tras ser instituido en 1976.

${ }^{2}$ El trabajo de Sanz Villanueva La novela española durante el franquismo (2010) incluye un subtítulo -"Itinerarios de la anormalidad"- que apunta a las circunstancias políticas y estéticas que limitaban la creación artística bajo la dictadura.
} 
particular, de aparente sencillez, que encubre una sensibilidad a flor de piel y una gran energía imaginativa. En su obra la voluntad testimonial se une a una inusitada capacidad fabuladora, generando situaciones e imágenes de gran poder sugestivo. El viraje de Matute hacia la literatura maravillosa o mágica, ${ }^{3}$ que no fantástica, según precisa Inmaculada de la Fuente (2002), obedece a una evolución, no a una ruptura: en sus fábulas siguen flotando las mismas pasiones humanas e idénticos desvaríos que en su narrativa anterior, de corte realista (p. 156). La misma Matute evita distinguir entre realidad e irrealidad, entre experiencia material y fantasía: "yo creo que la realidad no es solamente la realidad visible, sino que hay otra realidad, la invisible. Es a esa realidad a la que yo me aferré desde niña”, confiesa en una de las entrevistas que concedió (Gazarian, 1993, p. 16).

Cualquiera que sea la etiqueta en cuestión, no cabe duda de que en 1971 Matute envuelve su temática habitual en un traje mítico, proveniente de una misteriosa Edad Media. La torre vigía, junto con las novelas Olvidado rey Gudú (1996) y Aramanoth (2006), formará parte de la llamada "trilogía medieval", ambientada en el terreno de la literatura caballeresca, las leyendas medievales y los cuentos de hadas. Algunos han querido ver en esta trilogía una sombra de El señor de los anillos. Si bien es cierto (como veremos más adelante) que la trilogía medieval de Matute comparte algunos rasgos con la literatura fantasy británica, debe excluirse una imitación directa de la fantasía épica auspiciada por Tolkien, entre otras razones, según recuerdan Gracia y Ródenas (2011, p. 674), por la tardía difusión de su obra en España. ${ }^{4}$

A través de un narrador anónimo, La torre vigía cuenta en primera persona los años de formación de un joven aspirante a caballero, que se enfrenta a una realidad violenta, cargada de odio. Tanto en la casa paterna, donde experimenta una desgarradora soledad, como en el castillo del barón Mohl, adonde es enviado para armarse caballero, el chico solo conoce el desprecio y la crueldad. La novela representa un singular libro de caballerías y, al mismo tiempo, un Bildungsroman que incluye los ritos de paso a la edad adulta. En su camino a la madurez, el joven caballero aprende que las relaciones humanas se rigen por el rencor y la lujuria. Como es habitual en la narrativa de Matute, el universo novelesco está dominado por una visión negativa de las relaciones humanas: el chico morirá a los quince años de edad a manos de sus hermanos, envidiosos de su estatus en la corte.

La ambientación histórica y el uso de elementos propios de la cultura medieval -castillos, guerreros, luchas y armas- contribuyen a construir una representación del mundo como lugar hostil. El medievo recreado por la escritora rehúye las visiones sentimentales de la época para imponer una imagen despiadada de la sociedad humana. En La torre vigía los conflictos se resuelven de forma brutal y las pasiones

\footnotetext{
${ }^{3}$ A esta calificación más ambigua solía referirse la misma autora.

${ }^{4}$ La traducción al español de El señor de los anillos tardó veinte años en aparecer. El original se publicó en los años 1954-1955 y la versión española, en 1973.
} 
adquieren forma de actos obscenos. En lugar de la decencia y la honradez caballerescas, el mundo se rige por la fuerza del odio y la venganza, escenificados en una serie de ritos sangrientos. Con esta inversión de los ideales de caballería, Matute crea una especie de antinovela, una nueva novela de caballería ${ }^{5}$ o, como prefiere Germán Gullón (1996), una pseudonovela de caballería, en la cual son burlados los tópicos de la caballería (p. XXIV). Del mismo modo, queda subvertido el orden de la novela de iniciación (Bildungsroman), que no concluye con la integración del protagonista en la sociedad, sino que resulta (para su máxima decepción) en la renuncia, en la elección de la soledad y, finalmente, en la muerte.

Antes de considerar más a fondo los retos morales del protagonista de La torre vigía, es importante señalar el origen de su experiencia del terror. En el primer capítulo del libro, titulado "El árbol de fuego", el narrador adolescente nos cuenta el trauma de haber presenciado a los seis años la muerte en la hoguera de dos mujeres acusadas de brujería. El niño, obligado a asistir al acto por su propia madre, queda paralizado, tanto por la crueldad del rito como por el odio manifestado por la muchedumbre. La conmoción es tal que el niño vomita; acto seguido, pierde la voz durante algún tiempo. De nuevo se acusa a una de las víctimas, en este caso de haberle maldecido. Sin embargo, el narrador intuye que entre la "bruja" y él existía una especie de pacto, que le apartaba de los seres con quienes vivía: "Entre todos los hombres, mujeres, niños y bestias que presenciaron su tormento, me supe objeto de su especial elección" (Matute, 1994, p. 23). Así y todo, el "abominable cortejo de gritos y memorias" (Matute, 1994, p. 157) perseguirá al chico durante toda su (corta) vida, cada vez que resulte testigo (o partícipe) de alguna crueldad, como si el acto le hubiera marcado como una matriz de violencia.

Este episodio, además de vincular la histórica crueldad del hombre con las creencias prerracionales en brujas y maleficios, apunta al estatus elegido del niño. La particularidad reside en su mayor sensibilidad ética y en la renuncia a asumir la lógica del odio, del rencor y de la venganza. En el personaje anónimo de La torre vigía, Matute consigue dar expresión a su fe (luego frustrada) de que el hombre puede y debe oponerse al mal. Sin lugar a dudas, el problema de la violencia resulta central en esta novela y en toda la creación de Matute; y de un modo particular lo es la violencia y el abandono sufridos por los niños. El joven aprendiz de caballero debe superar la pérdida de su madre, la indiferencia de su padre y el antagonismo de sus hermanos mayores. Como consecuencia del desamor y de la crueldad conocidos en la infancia, llega a creer que en el mundo solo existe una ley y que "ésta la dictaban los guerreros" (Matute, 1994, p. 38).

Sorprende la agresividad concentrada en la novela, la presencia reiterada de escenas que desembocan en actos violentos, así como la abundancia de emociones, metáforas y símbolos que vaticinan diferentes amenazas. Entre las razones del mal

\footnotetext{
${ }^{5}$ Sobre el neo-caballerismo matutiano, v. la tesis doctoral de Jonathan Morgan Deen (2014).
} 
que se perciben en el texto, representadas con agudeza psicológica, está lógicamente el miedo -“viejo y conocido terror" (Matute, 1994, p. 89)-, la envidia (de sus hermanos y de otros escuderos no distinguidos por el barón) y también la humillación, los actos que hieren la dignidad o el orgullo, como los "tantos y tantos agravios" (Matute, 1994, p. 191) que sufren sus hermanos en los años de servicio. El narrador llega a entender su resentimiento y su conducta vengativa, pues "si injustos fueron ellos conmigo, injusto era el mundo con ellos, y todo cuanto mora en él" (Matute, 1994, p. 192). Otro aspecto relevante en este sentido es el abandono infantil: la falta de amor y de apoyo en los años de formación desemboca en "una suerte de odio errante y sin objeto preciso" (Matute, 1994, p. 42). El protagonista de La torre vigía descubrirá, tras años de angustia, que su sentimiento de aversión sí tenía un destinatario: a quien aborrecía era "a mi padre, a mi perdida infancia, al tiempo que los añoraba hasta el dolor” (Matute, 1994, p. 125).

Aparte de este penetrante análisis psicológico, Matute logra integrar en el texto un imaginario simbólico, poblado de brujas, demonios, seres fabulosos y animales fantásticos, que potencia el clima inquietante de la narración. La novela está repleta de elementos simbólicos: contrastes entre el blanco y el negro, la torre vigía, caballos, halcones, jabalíes, el viento acechante que provoca "un largo escalofrío", al tiempo que despierta en el personaje "una oscura sed de matar o aniquilar" (Matute, 1994, p. 99). En estas situaciones de tensión suele aparecer un enorme dragón, "con la cabeza alta y los ojos de oro" (Matute, 1994, p. 131), en cuyo lomo se erizan las lanzas de los guerreros. El viento insistente y el dragón funcionan como presagios de la violencia, símbolos de una fuerza ancestral, indomable, que "tiene presos" a los personajes. A propósito de este texto, Kathleen M. Glenn (1990) comenta muy acertadamente que su simbolismo ligado a ciertos animales remite al Apocalipsis de san Juan (pp. 24-25). Por poner un ejemplo, en la novela de Matute el dragón aparece en los momentos de máxima brutalidad, al igual que en el Libro de las Revelaciones, donde es comparado con "la serpiente antigua, que se llama Diablo y Satanás, quien engaña a todo el mundo" (Ap 12.9). Para Glenn, la visión que el narrador tiene la noche de su muerte -un joven guerrero apoya su pie sobre la testa de un dragón- apunta a las representaciones tradicionales de San Jorge, aunque en el caso de nuestro protagonista ese triunfo resulte más bien ilusorio.

Podría afirmarse que la inclusión de elementos fantásticos permite abrir puertas a la imaginación y, con ello, encontrar una salida a las injusticias del mundo representado. En la novela de Matute, la realidad mítica del medioevo, a pesar de revestirse de elementos propios de esa época, transmite preocupaciones muy modernas, marcadas por la incomunicación, la violencia y el carácter conflictivo de las relaciones humanas. Lo medieval y lo fantástico conforman un escenario propicio para resaltar la violencia que, sin embargo, tiene carácter eterno, y de ahí el valor universal del relato. 
Lo que acabo de plantear exige una aclaración teórica. ¿A qué género o sub-

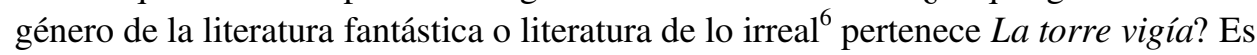
una pregunta difícil de contestar de manera que no admita discusión alguna. La novela de Matute combina acontecimientos de carácter maravilloso, mítico y legendario; al mismo tiempo sitúa su historia en un tiempo y espacio realistas (el medievo centroeuropeo), que proporcionan una sensación de cotidianidad, además de integrar elementos prerracionales y simbólicos. La combinación de recursos tan dispares dificulta hablar de una estética coherente. Por otra parte, los géneros de lo irreal tampoco suelen definirse de una manera unívoca. Sobre el más popular de ellos en la actualidad, lo fantasy, Alfons Gregori (2015) escribe que es "un gran cajón de sastre de carácter escasamente operativo", aunque, advierte, "a menudo bastantes estudios lo utilizan como marco de actuación sin llegar a definirlo" (p. 25). Si tomamos en consideración la distinción que en sus Strategies of Fantasy (1992) hace Brian Attebery entre la fantasía como género de literatura popular, o bien como modo sofisticado de narrar, marcado por la autoreflexión y la subversión de las normas establecidas, La torre vigía se adscribe indudablemente a la segunda variante. Para Maggie Carol McCullar (2011), quien examina el grado de fantasticidad en el texto apoyándose en la teoría de Northrop Fry (Anatomy of Criticism, 1957), es decir, a partir de la relación que el protagonista mantiene con otros personajes, en La torre vigía el protagonista anónimo de la novela no sólo es superior a otros personajes a nivel moral, sino que es "el elegido", revestido de atributos mesiánicos (p. 50). Con ello, pertenece más al mundo de la fantasía que a la realidad.

Otro elemento que debe tomarse en cuenta a la hora de revisar el modelo literario de Matute es lo gótico. En La torre vigía encontramos varios elementos propios de esta estética oscura. La misma ambientación medieval, con sus castillos, batallas y ritos caballerescos, con la crueldad, el terror y la tortura, las desviaciones sexuales y las actitudes vampíricas del Ogro y de la Ogresa (el barón y la baronesa), remite al modelo gótico, aunque, como muy acertadamente ha puesto de manifiesto Janet Pérez (1993), se trata más bien de motivos y no una escritura plenamente gótica. Según precisa la investigadora norteamericana, el propósito primordial de Matute no es de cariz estético, ni fantástico, ni gótico. Por encima de cualquier motivación artística, en su escritura predomina el afán de justicia social:

Lo que más gótico resulta en la obra de Matute son los espacios novelescos y las percepciones de la conciencia narradora, reflejadas en una retórica de miedo y pavor, misterio y oscuridad, que de manera expresionista exteriorizan la decadencia moral de la estructura social española. (Pérez, 1993, p. 50)

\footnotetext{
${ }^{6}$ Prefiero recurrir a este segundo término por considerarlo, de acuerdo con Gregori (2015), más amplio y, a la vez, más preciso, sin descalificar o restar valor a la raigambre teórica del término "fantástico".
} 
Con todo, las observaciones en torno a la estética empleada en la novela llevan a considerar La torre vigía y las otras dos partes de "la trilogía fantástica" de Matute como muestras de literatura fantasy, entendida esta como representación de lo maravilloso, y preferentemente lo maravilloso medievalizante, en convivencia con otros elementos fantásticos (v. Gregori, 2015, p. 10). Como comentamos anteriormente, lo fantasy representa un fenómeno muy amplio, que abarca una gran variedad de enfoques. Hay muchas formas de escribir fantasy y muchos elementos con que lo maravilloso puede hacerse presente en una obra literaria. La torre vigía ofrece las características básicas del género: un ambiente medievalizante, que entronca con las leyendas, los cuentos de hadas y los libros de caballería; motivos míticos y mágicos; el simbolismo y la lucha entre el Bien y el Mal (v. Niewiadomski \& Smuszkiewicz, 1990; Trębicki, 2007; Gregori, 2015). Como es bien sabido, en los orígenes de lo fantasy moderno se encuentran los autores británicos J. R. R. Tolkien y C. S. Lewis, quienes, con la publicación de sus obras maestras en los años 50 (El señor de los anillos de Tolkien; La trilogía cósmica y Las crónicas de Narnia, de Lewis), impulsaron el desarrollo del género. Tal como apunta Edward James (2012), Tolkien llegó a codificar el modelo al remitir el mundo de lo fantasy a la Edad Media y normalizar la idea del secondary world, en su caso un continente ficticio llamado Tierra Media (p. 70). Matute también ubica la trama de su novela en la Edad Media; sin embargo, la creación del mundo secundario en La torre vigía es ya cuestionable. Lo más interesante y sintomático es haber quebrantado la estructura típica del cuento maravilloso, la cual, según sostenía Tolkien (2002) en el ensayo "Sobre los cuentos de hadas" (así calificaba él sus textos), presenta cuatro propiedades específicas: la fantasía, la recuperación, la evasión y la consolación. Pues bien, la mayor desviación de Matute respecto al modelo tolkiano sería rectificar dicho sistema, eliminando la última característica. Para Tolkien (2002), la fantasía lleva a la consolación, a un buen final, llamado por él "eucatástrofe". Los acontecimientos del cuento deben girar, a veces repentinamente, para salvar al protagonista (y con él al mundo) de un destino terrible. La trilogía fantástica de Matute contrasta claramente con este carácter esperanzador de los relatos tolkianos. La visión crítica de la naturaleza humana no le permite ofrecer paliativos baratos en forma de desarrollos engañosos. Si la fantasía, según sugiere Tolkien en el citado ensayo, ha de expresar verdades importantes, en consonancia con las leyes del mundo real, en el caso de Matute la ley en cuestión debe ser "la ley dictada por los guerreros" (Matute, 1994, p. 38), que la escritora percibe como dominante y devastadora. Con ello llegamos a su preocupación esencial y al tema general de su arte: la expresión del dolor y la fortaleza ante la crueldad del mundo. En la obra de la escritora española la vida está marcada por una lucha continua entre el bien y el mal, en la que muchas veces triunfa el segundo. Cuando el narrador de La torre vigía, minutos antes de ser armado, observa a los más distinguidos caballeros de la corte, le asaltan los recuerdos de su brutal naturaleza y "toda clase de abusos sin sombra de disimulo" (Matute, 1994, p. 238) que ha cometido. 
Este joven no llegará a ser caballero; pasará, en cambio, a formar parte del grupo de personajes matutianos que denuncian y discuten las consecuencias de la violencia, la incomunicación, las carencias afectivas, etc. Su perplejidad ante el mundo observado convierte la obra de Matute en un espacio de profunda reflexión moral y en una manifestación de disconformidad con el entorno. Así sintetiza la autora su punto de vista en una conversación con Alicia Redondo (2009):

El mundo no funciona bien y, aunque tu vida personal sea feliz, el exterior te atañe, entra por debajo de las puertas, te agrade y te incita a levantarte contra él. Y no estoy hablando solo de la protesta social, sino de una protesta generalizada que nace ante el mundo que vivimos. La literatura es, en realidad, una protesta y una gran pregunta sobre la vida. Yo no propongo soluciones, yo planteo problemas. Es importante que la gente no cierre los ojos y no se tape los oídos. No decir amén ante lo que no nos gusta. (p. 150)

Desde esta perspectiva, escribir equivale a denunciar las injusticias, a conmover y a reivindicar un mundo más solidario. En un momento de tensión, el narrador de La torre vigía dice sentir "una gran amargura" que le avisaba de "algo que había en el mundo, o en los hombres, que manaba veneno", un veneno, según añade a continuación, era suficiente para corroer los hechos más inocentes y más hermosos, "como podía serlo, acaso, el amor entre hermanos" (Matute, 1994, p. 195). En esta escena de enfrentamiento entre el narrador y sus hermanos mayores, Matute retoma el motivo del cainismo y de la envidia, muy presente en su narrativa y en la literatura española en general.

Los hermanos del joven protagonista le persiguen envidiosos de sus privilegios en la corte, "con un odio tan maduro que adivinábase largamente acariciado" (Matute, 1994, p. 195). Sus figuras oscuras reaparecen a lo largo de la novela. Al final del relato salen de entre los abedules en la orilla del Gran Río para matar al hermano menor: "Oí tres gritos, y me atravesaron tres nombres hermanos [...]; sentí las puntas de tres lanzas, atravesándome una y mil veces" (Matute, 1994, p. 247). Las repetidas referencias a los hermanos como "tres jinetes negros", según anota Glenn (1990), evocan nuevamente el Libro de las Revelaciones y sus cuatro jinetes del Apocalipsis, representantes de los males de la guerra (p. 24).

Resulta pertinente subrayar el énfasis puesto en la visión negativa de la realidad, no solo la realidad inmediata que circunda al protagonista, sino la realidad en general: la naturaleza y la historia humana. El conflicto fratricida y los enfrentamientos violentos entre guerreros se extienden a todos los hombres y a todos los tiempos. El muchacho agonizante contempla "las lágrimas de todas las madrugadas de la tierra" y de nuevo ve al dragón con "su lomo erizado de lanzas y guerreros" (Matute, 1994, p. 248), otra imagen maléfica, aviso de la guerra. La noción particular del tiempo en la novela -lo que ocurre aquí y ahora ocurre siempre- confiere a la experiencia del protagonista una dimensión universal. El chico confiesa haber percibido la figura siniestra del dragón amenazante en un pasado (y en un futuro) desconocido: 
Distinguí muchas veces en el río cien hombres con cien lanzas, a lomos de dragón. Todos ellos guerreros, y tan rubios, feroces y desdichados como yo. Y no podía explicarme por qué, al verlos, yo sabía qué había sucedido en otro tiempo, anterior o posterior. Ni por qué me hallaba en el centro de tan grande e insalvable soledad. (Matute, 1994, p. 138)

La tendencia a ver el mundo en su aspecto más hostil deja su rastro también en la matriz apocalíptica de la novela. Al igual que la escritora niega a su cuento de hadas un final feliz, en su revelación apocalíptica no incluye ninguna visión de la superación del mal. A diferencia de la literatura apocalíptica tradicional, en La torre vigía no hay esperanza de que en un futuro llegue un Dios que venza a Satanás. Según recuerda Glenn, los apocalipsis se escriben en tiempos de crisis: en este sentido hay una fuerte analogía entre la época de san Juan y la España de la posguerra, cuando escribe Matute. Lo que distingue el enfoque de la escritora española del modelo evangélico es que La torre vigía no introduce a un libertador mesiánico, ni un juicio final, para que reine la justicia y se enmienden todos los males. "El patrón del apocalipsis sigue el camino de la crisis, el juicio y la salvación. En La torre vigía faltan los dos últimos elementos" (Glenn, 1990, p. 27).

Lo que intensifica el dramatismo de la novela es el hecho de centrar la trama en un personaje adolescente, casi un niño. $\mathrm{Y}$ es que la insistencia en la temática infantil es otro de los ejes centrales de la narrativa matutiana. De modo similar a tantas otras novelas de la escritora, La torre vigía destaca la soledad del niño, abandonado por los padres y odiado por los hermanos mayores. El niño viene a representar, por un lado, la inocencia y la pureza de los ideales y, por el otro, el desamparo y el sufrimiento del ser humano. La escritora reconoció más de una vez la raíz autobiográfica de esta preocupación: sabemos que tuvo una infancia desgraciada, marcada por un sentimiento de desamor y desarraigo, además de vivir la guerra civil con solo once años. Posiblemente a consecuencia de esta experiencia traumática, muchos de los protagonistas de sus libros son niños no queridos, huérfanos, marginados e infelices, que huyen de las injusticias, sumergiéndose en la fantasía. En la entrevista concedida a Alicia Redondo (2009), Matute afirma que los niños, así como sus relaciones familiares (casi siempre opresoras), son muy importantes en su obra: "la infancia es la época más importante de los seres humanos, a la que, sin embargo, se respeta muy poco" (p. 151). A consecuencia de ello, Matute también rompe con el patrón clásico en lo que concierne a la novela como Bildungsroman. El aprendiz de caballero de $L a$ torre vigía va perdiendo sucesivamente la ilusión frente al mundo que le rodea. Pero en vez de asumir esta verdad como una de las "leyes que rigen el mundo" (y al contrario de lo que hacen tantos otros personajes en las novelas de iniciación), se niega a asumir esa condición inmoral de la sociedad. Antes que incorporarla, prefiere abandonarla. En este gesto dramático, medio suicida (aunque finalmente muera a manos de sus hermanos), Matute reúne las características básicas de su escritura: la 
protesta contra el desamor y la violencia, expresada en nombre de los que no tienen ni voz ni autoridad para formularla, y el fracaso de la misma. Varios investigadores destacan esta intención ética en su obra. Para Galdona Pérez (2001), la narrativa de Matute es "un grito de descontento" y, al mismo tiempo, "una herramienta de lucha contra la injusticia y la hipocresía" (p. 108). Aunque desprovista del aspecto consolador, y consciente de la naturaleza corrompida del hombre, La torre vigía hace un llamamiento a la paz: "el mundo no era un grito de guerra, ni se debía alcanzar la vida a través de la violencia, la rapiña o el engaño, como siempre habían visto mis ojos, y enseñado todos los hombres" (Matute, 1994, p. 212).

En esta fábula medievalizante, cuento de hadas o novela fantasy, Matute ha manifestado una vez más el anhelo persistente del bien, entendido como convivencia pacífica, libre de odio y de abusos. Las decisiones artísticas -la elección del protagonista (un niño) y del género literario (lo maravilloso medievalizante)- quedan supeditadas a esta intención ética de conmover, para, posiblemente, transformar al lector insensible a la miseria humana. Estamos ante una fantasía de corte moral que se debate entre los ideales más nobles y la desilusión.

El desenlace de la novela es tajante, tanto en el plano de la trama como en el plano ético. Al morir, el protagonista decide aniquilar los valores tradicionalmente enfrentados, incluida la oposición entre el bien y el mal. Los invalida, como si desautorizara la moral humana (¿no habrá resultado inútil?):

La espada negra se alzó de mis propias manos, y segó, para siempre, el orgullo, la crueldad, el valor y la gloria. "El Mal ha muerto", me dije. [...]. Entonces, la piedad regresó a mí, y, tal vez, el amor. Pero alcé la espada, y el amor, y la piedad, quedaron segados para siempre. Y me dije: "El Bien ha muerto". (p. 249)

Es una resolución sorprendente, que equivale al abandono de la lucha por las facultades y los valores deseados. Es notable el sentimiento de derrota y la actitud de renuncia, incluso teniendo en cuenta que el protagonista sobrevive a su propia muerte, pues él mismo nos cuenta la historia. La trama, sin embargo, además de cobrarse la vida del protagonista, destruye el mundo de los valores, lo reduce a la nada, sumiendo al lector en el nihilismo. ¿Será el único camino para liberarse del dolor? 


\section{REFERENCIAS BIBLIOGRÁFICAS}

Attebery, B. (1992). Strategies of Fantasy. Bloomington \& Indianapolis: Indiana University Press.

Casas, A., Roas, D. \& Gregori, A. (2017). Narrativa 1950-1960. En D. Roas (dir.), Historia de lo fantástico en la cultura española contemporánea (1900-2015) (pp. 57-69). Madrid \& Frankfurt am Main: Iberoamericana \& Vervuert.

Deen, J. M. (2014). La nueva novela caballeresca de Ana María Matute. [Tesis doctoral inédita defendida en la Texas Tech University]. Consultado el 15 de enero de 2018 en https://tu-ir. tdl.org/ttu-ir/bitstream/handle/2346/60591/DEEN-DISSERTATION-2014.pdf?sequence=1

Fuente, I. de la (2002). Mujeres en la posguerra. De Carmen Laforet a Rosa Chacel: historia de una generación. Barcelona: Planeta.

Galdona Pérez, R. I. (2001). Discurso femenino en la novela española de posguerra: Carmen Laforet, Ana María Matute y Elena Quiroga. Santa Cruz de Tenerife: Universidad de La Laguna.

Gazarian, M. L. (1993). El lenguaje ningún o el mundo interior de AMM. En J. Roy, M. L. Gazarian, M. E. W. Jones \& J. Pérez (eds.), The Literary World of Ana Maria Matute (pp. 11-18). Coral Gables: University of Miami.

Glenn, K. M. (1990). Apocalyptic Vision in Ana María Matute's La torre vigía. Letras Femeninas, $16,21-28$.

Gracia, J. \& Ródenas, D. (2011). Historia de la literatura española, VII: Derrota y restitución de la modernidad. 1939-2010. Barcelona: Crítica.

Gregori, A. (2015). La dimensión política de lo irreal: el componente ideológico en la narrativa fantástica española y catalana. Poznań: Wydawnictwo Naukowe UAM.

Gullón, G. (1996). La singularidad de la narrativa de Ana María Matute. En A. M. Matute, Primera memoria (pp. V-XXIX). Barcelona: Destino.

James, E. (2012). Tolkien, Lewis and the explosion of genre fantasy. En E. James \& F. Mendlesohn (eds.), The Cambridge Companion to Fantasy Literature (pp. 62-78). Cambridge: Cambridge University Press.

McCullar, M. C. (2011). Other Worlds, Other Words: Ana María Matute's Fantasy. [Tesis doctoral inédita defendida en University of Colorado]. Consultado el 15 de enero de 2018 en https://scholar.colorado.edu/span_gradetds/1/

Matute, A. M. (1994). La torre vigía. Madrid: Plaza y Janés.

Niewiadomski, A. \& Smuszkiewicz, A. (1990). Leksykon polskiej literatury fantastycznonaukowej. Poznań: Wydawnictwo Poznańskie.

Pérez, J. (1993). Aspectos de lo gótico en la obra de Ana María Matute. En J. Roy, M. L. Gazarian, M. E. W. Jones \& J. Pérez (eds.), The Literary World of Ana Maria Matute (pp. 35-51). Coral Gables: University of Miami.

Redondo, A. (2009). Mujeres y narrativa: otra historia de la literatura. Madrid: Siglo XXI.

Roas, D. (dir.) (2015). Historia de lo fantástico en la cultura española contemporánea (1900-2015). Madrid \& Frankfurt am Main: Iberoamericana \& Vervuert.

Roas, D. \& Casas, A. (2008). Prólogo. En D. Roas \& A. Casas (eds.), La realidad oculta: cuentos fantásticos españoles del siglo XX (pp. 9-54). Palencia: Menoscuarto.

Sanz Villanueva, S. (2010). La novela española durante el franquismo. Itinerarios de la anormalidad. Madrid: Gredos.

Tolkien, J. R. R. (2002). Árbol y hoja (J. C. Santoyo \& J. Santamaría, trad.). Barcelona: Minotauro.

Trębicki, G. (2007). Fantasy. Ewolucja gatunku. Cracovia: Universitas. 